\title{
SABERES E EXPERIÊNCIAS DE GESTANTES SOBRE AUTOCUIDADO PUERPERAL E CUIDADO DO/A RECÉM-NASCIDO/A MEDIANTE PRÁTICAS EDUCATIVAS
}

\author{
KOWLEDGE AND EXPERIENCES OF PREGNANT \\ WOMEN ABOUT PUERPERAL SELF-CARE AND

\section{CONOCIMIENTOS Y EXPERIENCIAS DE LAS MUJERES EMBARAZADAS SOBRE EL AUTOCUIDADO PUERPERAL Y EL CUIDADO DEL RECIÉN NACIDO A TRAVÉS DE PRÁCTICAS EDUCATIVAS}

\author{
Jessica Fonseca Mota ${ }^{1}$ \\ Mariza Silva Almeida ${ }^{2}$ \\ Gessica Cerqueira Magalhães ${ }^{3}$ \\ Venícia Conceição Souza ${ }^{4}$ \\ Joise Magarão Queiroz Silva ${ }^{5}$ \\ Karla Ferraz dos Anjos ${ }^{6}$
}

Como citar este artigo: Mota JF, Almeida MS, Magalhães GC, Souza VC, Silva JMQ, Anjos KF. Saberes e experiências de gestantes sobre autocuidado puerperal e cuidado do/a recém-nascido/a mediante práticas educativas. Rev baiana enferm. 2021;35:e41929.

\begin{abstract}
Objetivo: analisar saberes e experiências de gestantes sobre o autocuidado puerperal e cuidado do/a recém-nascido/a mediante práticas educativas. Método: estudo qualitativo, com 16 gestantes que frequentavam o pré-natal em maternidade pública de Salvador, Bahia. Aplicou-se, na coleta de dados, roteiro de entrevista semiestruturado e práticas educativas em saúde. Utilizou-se análise de conteúdo na modalidade temática. Resultados: emergiram três categorias: autocuidado no período pós-parto: relevante e indispensável; neonato e amamentação: aprender para melhor cuidar; e práticas educativas na gestação: o resultado esperado. Evidenciou-se necessidade e relevância das práticas educativas desde a gestação, contudo valorizou-se o cuidado do/a recém-nascido/a em relação ao autocuidado da mulher, podendo influenciar no (auto)cuidado das envolvidas. Considerações finais: as práticas educativas realizadas durante o pré-natal ofertaram subsídios para o empoderamento e a autonomia das mulheres ao retornarem ao domicílio, contudo, quando realizadas, distanciavam-se do autocuidado feminino, pois tendiam a valorizar apenas os cuidados destinados ao/a recém-nascido.
\end{abstract}

Descritores: Gestantes. Cuidado Pré-Natal. Educação em Saúde. Conhecimento. Período Pós-Parto.

Enfermeira Obstetra. Centro de Parto Normal da Maternidade Professor Barros Lima, Casa Amarela. Recife, Pernambuco, Brasil. jessicamotta.enf@outlook.com. http://orcid.org/0000-0002-8448-2689.

Enfermeira. Doutora em Enfermagem. Professora Adjunta da Universidade Federal da Bahia. Salvador, Bahia, Brasil. http://orcid.org/0000-0002-7|45-8727.

Enfermeira. Pesquisadora Independente. Salvador, Bahia, Brasil. http://orcid.org/0000-000 I-8|49-3।74.

Estudante de Enfermagem. Universidade Federal da Bahia. Salvador, Bahia, Brasil. http://orcid.org/0000-0003-08 I9-5300.

Enfermeira. Mestre em Enfermagem. Pesquisador independente. http://orcid.org/0000-0002-5| 42-I I 50.

Enfermeira. Doutora em Enfermagem. Professora da Unime Salvador. Salvador, Bahia, Brasil. karla.ferraz@hotmail.com. https://orcid.org/0000-0002-5453-8303. 
Objective: to analyze the knowledge and experiences of pregnant women about puerperal self-care and newborn care through educational practices. Method: qualitative study with 16 pregnant women who attended prenatal care in a public maternity hospital in Salvador, Bahia. A semi-structured interview guide and health educational practices were applied in data collection. Content analysis was used in the thematic modality. Results: three categories emerged: self-care in the postpartum period: relevant and indispensable; newborn and breastfeeding: learning the best care; and educational practices during pregnancy: the expected result. The need and relevance of educational practices since pregnancy were evidenced; however, the newborn care was valued in relation to the woman's self-care, and may influence the (self-)care of those involved. Final Considerations: the educational practices performed during prenatal care offered subsidies for women's empowerment and autonomy when returning home; however, when performed, they distanced themselves from female self-care, as they tended to value only the newborn care.

Descriptors: Pregnant Women. Prenatal Care. Health Education. Knowledge. Postpartum Period.

Objetivo: analizar los conocimientos y experiencias de las mujeres embarazadas sobre el autocuidado puerperal y el cuidado de los recién nacidos a través de prácticas educativas. Método: estudio cualitativo con 16 mujeres embarazadas que frecuentaron la atención prenatal en un hospital público de maternidad en Salvador, Babia. En la recogida de datos, se aplicó una guía de entrevista semiestructurado y prácticas educativas en salud. El análisis de contenido se utilizó en la modalidad temática. Resultados: surgieron tres categorías: autocuidado en el periodo posparto: relevante e indispensable; neonato y la lactancia materna: aprender a cuidar mejor; y prácticas educativas durante el embarazo: el resultado esperado. Se evidenciaron la necesidad y la relevancia de las prácticas educativas desde el embarazo, sin embargo, se valorizó el cuidado del recién nacido en relación con el autocuidado de la mujer, y puede influir en el (auto)cuidado de las involucradas. Consideraciones finales: las prácticas educativas realizadas durante el cuidado prenatal ofrecian subsidios para el empoderamiento y la autonomía de las mujeres al regresar a casa, sin embargo, cuando se realizaban, se distanciaban del autocuidado que de la mujer, ya que tendian a valorar únicamente el cuidado destinado al recién nacido.

Descriptores: Mujeres Embarazadas. Atención Prenatal. Educación en Salud. Conocimiento. Período Posparto.

\section{Introdução}

Entre as ações assistenciais realizadas durante a gestação, têm-se o acompanhamento pré-natal. Segundo o Ministério da Saúde, este é o momento propício para a promoção do cuidado integral da gestante, que vai além de aspectos biológicos e inclui a utilização de estratégias educacionais dinâmicas que estimulem a participação ativa das mulheres na construção do conhecimento, em temas concernentes ao ciclo gravídico-puerperal $^{(1)}$.

Desse modo, a qualidade da assistência pré-natal não se restringe aos aspectos quantitativos, a exemplo, do número de consultas ou do início precoce do pré-natal. Devem ser incorporadas estratégias com abordagem holística e resolutiva que busquem possibilitar à mulher vivenciar o seu ciclo reprodutivo de forma positiva, com menos riscos de complicações no puerpério e maior sucesso na amamentação ${ }^{(2)}$.

O/A enfermeiro/a, enquanto educador/a, assume importante responsabilidade no cuidado à saúde, ao desenvolver suas ações educativas pautadas na individualidade, integralidade, autocuidado e empoderamento feminino. No caso das gestantes, deve capacitá-las para a tomada de decisões autônomas e melhoria na sua qualidade de vida $(\mathrm{QV})^{(3)}$.

Ao estimular a mulher para seu autocuidado, a/o enfermeira/o contribui para sua independência quanto às demandas de saúde, estimulando-a a tornar-se corresponsável pelo próprio cuidado. Todavia, para que isso seja possível, essa/e profissional precisa exercer a escuta qualificada de maneira aberta e horizontal. É preciso propiciar um espaço de aprendizado mútuo, no qual não há verdade absoluta, mas, sim, relativa, passível de ser questionada, complementada ou superada por outros saberes ${ }^{(4)}$.

Nesse sentido, a atividade educativa é reforçada por políticas e programas públicos. Estes constituem-se em instrumentos necessários para a promoção da saúde das mulheres. Apesar de sua garantia ser o direito feminino, tem-se o paradoxo de que a mulher, mesmo com frequência 
ativa no pré-natal e gestação saudável, chega ao puerpério com déficit de conhecimento e insegurança para autocuidar-se e para prestar cuidados adequados ao/a recém-nascido/a $(\mathrm{RN})^{(5)}$.

Dentre as estratégias educacionais em saúde, têm destaque as oficinas educativas que, ao oportunizar o compartilhamento de sentimentos e vivências de mulheres, podem minimizar as lacunas do serviço público de saúde e contribuir para reforçar a sensação de segurança, bem-estar e tranquilidade em relação às demandas que surgem no ciclo gravídico-puerperal ${ }^{(6)}$. Nessa perspectiva, insere-se o modelo educativo dialógico, que se fundamenta na construção de relações simétricas entre o/a profissional e o/a educando/a, nas necessidades das mulheres e na formação da sua autonomia, com o intuito de superar o autoritarismo e a fragmentação do cuidado $^{(4)}$. As mulheres orientadas e informadas terão certamente mais segurança, confiança e menos ansiedade para se autocuidarem e cuidarem do/a filho/a, quando retornarem ao domicílio após a alta hospitalar.

Dessa forma, o preparo das gestantes, apoiado em atividades educativas durante $\mathrm{O}$ pré-natal, é fundamental para o desenvolvimento do puerpério saudável, identificação de sinais de alerta de forma precoce e minimização de vulnerabilidades, aspectos indispensáveis para promoção da saúde e redução dos índices de morbimortalidade materna e neonatal.

Este estudo tem como objeto saberes e experiências de gestantes sobre o autocuidado puerperal e cuidado de recém-nascido/a adquiridos ao longo de sua vida. Como questão de pesquisa: Quais são os saberes e as experiências de gestantes, participantes em prática educativa, sobre o autocuidado puerperal e cuidado de recém-nascido/a? Desse modo, objetivou-se analisar saberes e experiências de gestantes sobre o autocuidado puerperal e cuidado do/a recém-nascido/a mediante práticas educativas.

\section{Método}

Estudo qualitativo que buscou, com base no desenvolvimento de práticas educativas em saúde com 16 gestantes, analisar seus saberes, experiências, crenças e atitudes direcionados ao autocuidado no puerpério e ao cuidado do/a RN, não se restringindo ao conhecimento adquirido no pré-natal, mas incluindo também aquele que é resultado de suas vivências pessoais e sociais anteriores. Os temas selecionados para as práticas educativas consideraram os relacionados ao período puerperal. Este foi realizado em uma maternidade pública de Salvador, Bahia, Brasil, unidade docente-assistencial de obstetrícia, neonatologia e saúde perinatal vinculada à Universidade Federal da Bahia (UFBA).

A coleta de dados ocorreu em agosto de 2019, na Casa da Gestante, Bebê e Puérpera (CGBP) que é uma residência anexa à maternidade, semelhante ao ambiente domiciliar, que acolhe e cuida de gestantes, puérperas e RNs com maior vulnerabilidade, com vistas à redução da morbimortalidade materna e perinatal. A unidade realiza práticas educativas regularmente, previamente agendadas.

Os critérios de inclusão adotados foram: ser gestante e estar matriculada no pré-natal (risco habitual e alto risco) da maternidade e apresentar condições cognitivas preservadas. O de exclusão foi ter idade inferior a 18 anos.

As gestantes que compareceram à CGBP, nos dois dias selecionados para o estudo, foram convidadas a participar. Não houve recusa ou desistência

As entrevistas semiestruturadas ocorreram, a princípio, em local reservado, com informações sociodemográficas, dados obstétricos e questões abertas norteadoras em relação ao seu conhecimento prévio adquirido no pré-natal atual ou mediante vivências anteriores sobre os cuidados após o parto, os cuidados com o/a RN e amamentação. Posteriormente, realizaram-se duas práticas educativas na sala de estar da CGBP, com duração aproximada de duas horas cada. Essas duas atividades foram realizadas pela pesquisadora, pela orientadora e por uma graduanda de enfermagem treinada. As entrevistas e as práticas educativas foram gravadas com uso de gravador de áudio e posteriormente transcritas. 
A adoção das práticas educativas como estratégia de coleta de dados permitiu às pesquisadoras tornarem-se partes integrantes do grupo, além de facilitar a compreensão da sua realidade em favor da construção coletiva do conhecimento. Este modelo educativo dialógico, como estratégia metodológica fundamentada na educação problematizadora, estimula o senso crítico e reflexivo, a autonomia e a corresponsabilização pela saúde. Em paralelo a essas vantagens, a capacidade de aprendizagem, ao se relacionar intrinsecamente com a curiosidade do/a educando/a, com as dinâmicas e as brincadeiras, pode produzir resultados mais satisfatórios e eficazes ${ }^{(4)}$.

Desse modo, ressalta-se que se buscou atender às necessidades educativas das gestantes, após a realização de questionamentos, explicações, orientações e discussão sobre os assuntos que a elas interessassem, de maneira que seus saberes e experiências prévias conduziram a atividade, não havendo necessidade de roteiro rigoroso estabelecido para os diálogos.

As práticas educativas tiveram início com uma dinâmica de apresentação. Seu objetivo foi aproximar e desenvolver vínculo entre as participantes. Objetos que simbolizavam o autocuidado materno e cuidados com o/a $\mathrm{RN}$ foram colocados em uma "caixa surpresa", para serem retirados pelas gestantes, um por vez. A intenção era tornar o ambiente propício para a troca de conhecimentos e de experiências entre elas, de maneira recíproca. As participantes foram acomodadas em círculo, para facilitar essa interação. Ao final da atividade, elas desenharam e/ou escreveram, em papel ofício, o conhecimento construído pelo grupo, com vistas a reforçar o aprendizado e sanar possíveis dúvidas. Na sequência, com uma palavra, avaliaram individualmente o significado da atividade.

Os dados emergidos dessas práticas foram analisados por meio da técnica de análise de conteúdo ${ }^{(7)}$, modalidade temática, com base nos três polos cronológicos: pré-análise, na qual foi realizada uma leitura flutuante; exploração de material, que consistiu na avaliação dos depoimentos convergentes, agrupando-os, com vistas a realizar inferências e interpretações; e tratamento dos dados, inferência e interpretação, momento em que foram realizadas a síntese e a seleção dos resultados ${ }^{(7)}$. Na etapa seguinte, foram extraídas as três categorias empíricas que emergiram dos dados, a saber: autocuidado no período pós-parto: relevante e indispensável; neonato e amamentação: aprender para melhor cuidar; e práticas educativas na gestação: o resultado esperado.

Estudo submetido à apreciação e análise do Comitê de Ética em Pesquisa (CEP) da maternidade onde foi desenvolvida a pesquisa, e aprovado sob o Parecer n. 3.471.324 e Certificado de Apresentação da Apreciação Ética n. 15832819.9.0000.531. Após esclarecimentos do estudo, as participantes assinaram e receberam uma cópia do Termo de Consentimento Livre e Esclarecido (TCLE). Como forma de manter o anonimato e a privacidade das participantes, foram utilizadas as siglas ENT = Entrevista e PE = Prática Educativa seguidas de número cardinal sequencial designado de acordo com a ordem de realização das entrevistas.

\section{Resultados e Discussão}

Com relação às 16 gestantes participantes, a idade média variou entre 21 e 39 anos; 12 autodeclararam-se negras e 4 pardas; 9 possuíam ensino médio completo, 4 superior completo e 3 superior incompleto; 11 eram casadas ou tinham união consensual; 1 declarou não trabalhar fora de casa; e a renda familiar variou entre $\mathrm{R} \$ 700,00$ e R\$4.000,00. Quanto aos dados obstétricos: 5 eram primigestas, 11 tinham vivências de gestações e partos anteriores, e 10 realizaram 6 ou mais consultas de pré-natal.

\section{Categoria 1 - Autocuidado no período pós-parto: relevante e indispensável}

As gestantes, quando indagadas sobre $\mathrm{O}$ conhecimento e a preparação para o autocuidado no puerpério construído ao longo de sua vida, expressaram desconhecimento. Demonstraram também a existência de uma lacuna de informação/orientação no pré-natal. Esses 
dados condizem com o afirmado em estudo ${ }^{(8)}$, de que essa é uma fase negligenciada pelos/as profissionais de saúde, em contraposição à supervalorização dada ao parto e aos cuidados com o/a $\mathrm{RN}^{(8)}$. Desse modo, quanto aos conhecimentos informaram:

No pré-natal ainda não falou, assim, no pós-parto o que é que vai ser. (ENT14).

Ainda não. Tenho muitas dúvidas, mas também tenho medo. Porque, primeira vez, assim, a gente tem medo. (ENT3).

Ainda não cheguei nessa fase aqui não. Só em relação ao parto, mas o após o parto não. Ainda não. (ENT12).

O puerpério, conhecido também como "resguardo" ou "quarentena", inicia-se após o parto, especificamente após a expulsão da placenta, e termina quando as modificações locais e gerais voltam ao estado anterior à gestação, acompanhado do retorno da função reprodutiva ${ }^{(9)}$. Esse período tem maior possibilidade de intercorrências clínicas, como anemias, hemorragias, infecções. Além disso, é influenciado por questões de ordem psicossocial relacionadas ao vínculo com o/a filho/a, ao relacionamento interpessoal, às mudanças nos arranjos familiares, à sexualidade e à autoestima. Esses aspectos justificam a complexidade desse período ${ }^{(10)}$.

Similarmente aos resultados deste, foi visto em estudo ${ }^{(11)}$ realizado com 50 puérperas na Argentina, a consequência da deficiência do ensino do autocuidado puerperal em serviços de saúde. Os autores alertam que esse importante problema de saúde pública relaciona-se intrisecamente com o aumento da morbimortalidade materna, o que retoma a necessidade de identificar, nessa população, os aspectos do autocuidado, bem como fatores atenuantes e agravantes.

No que se refere ao quesito higiene pessoal, algumas gestantes demonstraram ter conhecimento, entretanto ficou visível a perpetuação de tabus a respeito do primeiro banho após o parto. A lavagem da cabeça no puerpério, embora considerassem um cuidado higiênico importante, ainda era permeada pelo sentimento de medo, como afirmaram:
Eu não sabia que, quando a gente tem o parto normal, não pode logo tomar banbo e lavar a cabeça, só que eu não tenho ninguém para me orientar. (PE1).

Eu não sei se isso seria recomendado, mas eu acho que não vejo a necessidade de lavar o cabelo. (ENT12).

O povo [pessoa] tem essa mania de falar: não pode lavar o cabelo! Mas eu lavei e não teve problema nenhum! Depois ainda escovei, pranchei e não teve problema nenhum. (PE2).

Nesse sentido, estudo ${ }^{(12)}$ realizado com puérperas no Rio Grande (RS) constatou que o argumento para essa norma cultural conserva o mito de "risco de comprometimento mental" e até mesmo de morte ocasionados pela inversão do fluxo sanguíneo, recomendando o espaço de tempo de 7 a 20 dias sem lavar o cabelo. Aconselha-se, portanto, a problematização dessa prática, ainda no período gestacional, a fim de esclarecer e incentivar esse e demais cuidados higiênicos adequados para melhor manutenção da saúde materna no período pós-parto.

As necessidades de saúde das mulheres no período puerperal devem estar relacionadas de forma intrínseca aos seus contextos ambiental e sociocultural e às suas inter-relações também. Nesse sentido, esse entendimento é fundamental no trabalho do/a enfermeiro/a, para que possa compreender o processo de saúde e doença que repercutirá na definição e implementação de ações para promoção da saúde ${ }^{(13)}$.

Dessa forma, os fatores culturais exercem forte influência nos hábitos alimentares durante o puerpério. Neste estudo, o autocuidado materno visou prioritariamente o bem-estar do/a $\mathrm{RN}$, de forma que a restrição a certos alimentos teve como objetivo prevenir cólicas, gases e aumentar a produção láctea. Ademais, ainda se tem a ideia de que a ingestão de alimentos considerados lactogênicos, como o milho, resulta em maior produção láctea e que a ingestão de frutas cítricas causa refluxo na criança:

Eu acho que tem que comer fruta, essas coisas, porque as coisas que a gente come vai passar para o bebê através do leite. Aí pode passar cólica, essas coisas. (ENT1).

Além de também de ter coisas que não é legal, porque passa pro bebê no leite, aí dá gases. A gente amamenta, $e$ o bebêfica cheio de gases. (PE8).

Eu achava que o milho que fazia aumentar o leite! (PE5). 
Era refluxo, e eu também estava me alimentando errado. Eu tava bebendo coisas cítricas e não pode. (PE11).

Com resultados semelhantes, estudo ${ }^{(14)}$ revela que as orientações recebidas por puérperas quanto à sua alimentação visavam o sucesso do aleitamento materno (AM) e enfatizavam os benefícios de uma alimentação adequada para a saúde neonatal, sem considerar os benefícios maternos $^{(14)}$. De modo semelhante, outro estudo realizado com 30 mulheres em São Paulo também deixa evidente que as mães associavam a ingestão de frutas cítricas a malefícios ao neonato $^{(15)}$.

Não obstante, ressalta-se que a privação de certos nutrientes importantes pode trazer prejuízos à mulher e ao desenvolvimento da criança. Em regra, o puerpério fisiológico não requer dietas especiais ou restritivas, contudo deve-se incentivar a ingestão de alimentos saudáveis, de maneira individualizada, que promovem um adequado funcionamento intestinal, além de uma boa ingestão hídrica ${ }^{(9)}$.

No que se refere a um hábito comumente incentivado pelas mulheres, destaca-se o "resguardo" que, neste estudo, abrangeu desde o repouso relativo em relação às atividades domésticas até a abstinência sexual prolongada como ato de respeito à "quarentena":

Eu acho que muitas coisas não pode fazer, tipo pegar peso, não fazer muita força, muito exercício, que está recente e pode complicar. (ENT10).

Eu acho que é ficar deitada, pegarpeso, ter relação. Se foi normal, dois meses; cesárea é três. (ENT11).

Tem várias coisas que são proibidas [...] A mulber deve ter cuidado com seu resguardo. (ENT14).

Há relatos de tradições culturais que se perpetuam por muitas gerações, com a finalidade de recuperar ou "fechar o corpo" após o parto, para alcançar uma boa adaptação à nova rotina e, desse modo, auxiliar na recuperação do útero, bem como evitar hemorragias ${ }^{(12)}$. No que se refere à restrição sexual, isso se dá em virtude de fatores psicológicos, concepções culturais e fatores hormonais, como o aumento da prolactina, que levam à diminuição da libido, da lubrificação vaginal e do desejo sexual. É recomendado que o retorno à atividade sexual seja iniciado gradativamente e vá evoluindo mediante a confiança, o respeito mútuo e o bem-estar do casal ${ }^{(9)}$.

Outro fenômeno fisiológico mencionado refere-se ao desconhecimento das mulheres relacionado à loquiação - perda sanguínea vaginal após o parto -, bem como sobre os sinais de alerta para certas intercorrências que implicam no retorno imediato à maternidade. Neste estudo, houve o desejo da abordagem sobre os lóquios nas práticas educativas desde a gestação:

Eu aprendi do sangramento após o parto que você falou, que começa escuro e termina claro. Eu não sabia. (PE7).

Eu aprendi também que você falou sobre o sangramento né, que eu não sabia que poderia acontecer isso de ficar com dor, de ter um corrimento com mau cheiro, que isso teria que procurar [...] a unidade, que isso seria um sinal de alerta. Isso foi muito importante. (PE1).

Vale destacar que as infecções puerperais estão entre as principais causas de mortalidade materna, porém a maioria delas pode ser evitada por meio do ensino do autocuidado sobre higiene adequada e pelo reconhecimento e tratamento precoces dos sinais de infecção ${ }^{(16)}$. Nesse sentido, é crucial o conhecimento relacionado às características dos lóquios, seu aspecto e odor, pois tais alterações poderão demandar atendimento precoce, a fim de evitar complicações ${ }^{(12)}$.

Como reforço, intervenção educativa realizada com 40 puérperas no Peru demonstrou sua importância para aumentar o conhecimento do autocuidado puerperal, já que medidas educacionais preventivas podem possibilitar redução da readmissão hospitalar e autossuficiência materna para tomada de decisões seguras quanto à sua saúde e minimização da sua vulnerabilidade ${ }^{(17)}$.

\section{Categoria 2 - Neonato e amamentação: aprender para melhor cuidar}

Dentre os cuidados neonatais, tem destaque a limpeza adequada do coto umbilical, que deve ocorrer a cada troca de fralda e após o banho do/a RN com solução de álcool a 70\%, antisséptico adequado para prevenção de infecção. A falta de higienização ou higiene inadequada pode causar infecção e pôr em risco a vida do neonato ${ }^{(18)}$. Nesta pesquisa, as mulheres 
demonstraram conhecer o cuidado adequado do coto umbilical, no que se refere ao produto utilizado e à técnica correta, contudo necessitavam de esclarecimentos quanto à manipulação e periodicidade:

\begin{abstract}
Assim, até onde eu sei, só lavar e secar mesmo, e o único produto mesmo é o álcool a $70 \%$ [...] deixar ele cair naturalmente, não requer o uso de pomadas, cremes de nada, nem abafar. (PE14).

Com certeza o bebê sente dor minha filha [...] se você dá banho 3 vezes por dia, você vai ter que fazer a limpeza 3 vezes ao dia. Se dá banho 1 vez por dia, vai limpar uma vez por dia. (PE9).
\end{abstract}

Resultados díspares foram encontrados em estudo realizado com puérperas em Fortaleza, no qual 60\% delas afirmaram haver a necessidade de cobertura do coto com curativos ou faixas e $54 \%$ desconheciam os produtos adequados para a higienização ${ }^{(19)}$. Dessa forma, a informação veiculada pelo/a enfermeiro/a deve ser completa e com linguagem harmônica à compreensão materna.

No quesito referente à troca de fralda, embora relatassem conhecimento adequado quanto à periodicidade e higiene correta da genitália, ainda persistiam dúvidas em relação a esse cuidado, como uso de lenço umedecido, pomadas, talco, amido de milho, dentre outros:

\begin{abstract}
Aí tenho dúvidas nas pomadas que usar. Tem gente que usa maisena, não pode talco, o lenço umedecido, se é pra usar ou só água morna? Aí eu tenho muitas dúvidas mesmo. (PE14).

Saber o borário de troca né, porque você não vai deixar uma criança que botou uma fralda de manhã e tirar tarde da noite [...] Aqui ó, de cima pra baixo, dessa região da barriga pra baixo [...] ela pode pegar uma infecção e você não saber o que é que o bebê tanto chora. (PE9).
\end{abstract}

De modo similar, estudo realizado com puérperas demonstrou que tinham domínio sobre o material para higiene e troca de fralda, contudo manifestavam dúvidas sobre a higienização da região íntima de crianças do sexo feminino ${ }^{(19)}$.

Dentro dessa conjuntura, quando problematizadas a respeito do posicionamento correto do neonato no berço, notou-se, entre as gestantes, que ainda externavam dúvidas e insegurança para mencionar o que seria ou não adequado:

Sempre botei [coloquei] de lado. Tem mães que botam [colocam] assim. (PE10).
Tem mães que colocam o bebê para baixo. (PE13).

Os médicos fala que é correto colocar a filha pra cima né? Não sei se é certo, não sei se é errado. Quero aprender aqui. (PE9).

Estudo com primigestas demonstrou resultados semelhantes, ao revelar o desconhecimento das mães, no que se refere à postura da criança para dormir $^{(20)}$. Em contrapartida, outro estudo ${ }^{(21)}$ demonstrou que as mães tinham intenção de colocar o/a RN para dormir em posição supina. Salienta-se, portanto, a importância de orientar e informar, ainda no pré-natal, a importância da posição dorsal como uma prática benéfica, que reduz o óbito entre lactentes, sobretudo por ser uma medida prática e de baixo custo ${ }^{(21)}$.

No que tange à amamentação, observou-se que a construção desse conhecimento dava-se durante as práticas educativas realizadas na maternidade, em dias previamente aprazados, com ênfase nos seguintes aspectos: cuidados com as mamas; importância do aleitamento materno exclusivo (AME); posicionamento e pega adequados e malefícios dos confundidores de mamada. Essas práticas são altamente positivas para reforçar a necessidade dessas atividades durante o pré-natal e facilitar e potencializar o processo de amamentação, como se nota a seguir:

Já! Aqui no grupo de gestante, elas ensinam e a gente
aprende né, que não pode dar bico nem a mamadeira;
que tem que dar o peito até os 6 meses, pra poder a crian-
ça ficar forte, saudável, inteligente e também os cuidados
da aréola da mama. Dar direitinho o peito à criança pra
poder não pegar errado. (ENT13).

No curso da gestante, na casa da gestante, também na consulta, eu recebi orientações [...] sobre confusão de bicos, que o uso da chupeta não é legal, a mamadeira também não é legal [...] foi um curso muito completo para mim. Até boje eu não esqueci. (ENT14).

Sim, a enfermeira obstetra que me falou para não passar sabonete, para tomar banho de sol, esses cuidados diários. (ENT2).

No estudo realizado com nutrizes de uma maternidade de Rondônia, após uma intervenção educativa sobre AME, notou-se que houve aumento da autoeficácia na amamentação e da frequência do AME. Desse modo, reitera-se a relevância do ensino dos benefícios dessa prática e dos riscos do desmame precoce, bem como do manejo correto da amamentação desde 
a gestação, a fim de elevar habilidades e autoconfiança materna ${ }^{(22)}$.

Em se tratando do manejo da amamentação, um dos maiores problemas relatados pelas mulheres, resultantes de vivências anteriores, referiu-se à pega inadequada da criança no seio materno, que ocasionou fissuras mamilares, dor intensa e aumento do estresse. Diante disso, observou-se que o desconhecimento do manejo adequado da lactação pode levar à introdução precoce de outros alimentos, além de causar sofrimento, conforme relatado a seguir:

\footnotetext{
Agora eu sofri muito pra amamentar. O meu peito feriu todo, feriu muito, muito mesmo [...] Dei cremogema a minha filha. Ela só vivia chorando! Eu acho que, além de eu não ter bico, eu também não sabia amamentar. (PE1).

Sofria quando eu tava tentando amamentar [...] os meninos choravam de um lado e eu chorava do outro. E eu falava: tira esse menino do meu peito, tira pelo amor de Deus! Meu esposo chorava do outro lado, e eu ficava mais nervosa [...] Eu acho que a falta de conbecimento, que eu não tive, eu nunca sabia que a pega correta [...] (PE2).

Porque rachado ou não eu dava, o leite escorria, o bico do meu peito parecia que ia soltar. Vinha o sangue assim, ó, nos dois. (PE7).
}

Apesar da comprovação de que a amamentação tem impacto positivo na redução da morbimortalidade infantil, o desmame precoce é um importante problema de saúde pública no Brasil, uma vez que somente $41 \%$ dos menores de seis meses beneficiam-se do AME, de forma que a duração mediana é 1,8 meses. Esses dados estatísticos permitem a reflexão quanto à interferência de fatores biopsicossociais no processo de amamentação, mesmo na presença do conhecimento adequado. Contudo, ressalta-se que falsas crenças relacionadas ao leite materno, à suposta necessidade de protrusão do mamilo, à naturalização da dor na amamentação, dentre outras, secundárias à orientação inadequada, influenciam negativamente no ato de amamentar ${ }^{(23)}$.

Salienta-se que a pega no seio e o posicionamento adequado são cruciais para o esvaziamento eficiente das mamas, bem como para prevenir traumas mamilares. Em contrapartida, a técnica incorreta poderá levar à diminuição da produção láctea e ao ganho de peso da criança inferior ao esperado. Além disso, é imprescindível esclarecer que mamilos planos ou invertidos dificultam, mas não impossibilitam a amamentação, pois a criança deve abocanhar a aréola $^{(24)}$.

Sabe-se que ainda predominam a insegurança e o despreparo materno em prestar cuidados adequados à criança e vivenciar a amamentação. Estes são ocasionados, em alguns casos, pela falta e/ou déficit de orientação profissional durante o pré-natal ou até mesmo no momento da alta da maternidade ${ }^{(9)}$. Diante dos resultados deste estudo, recomenda-se o desenvolvimento de ações educacionais integrais na gestação, pois é direito da futura mãe conhecer como se dará o cuidado adequado do seu/sua $\mathrm{RN}$, a fim de atenuar as complicações neonatais.

\section{Categoria 3-Práticas educativas na gestação: o resultado esperado}

Neste estudo, tornou-se evidente que a perspectiva dialógica propicia maior interação entre as gestantes, ajuda na fixação do aprendizado e na compreensão de questões que, muitas vezes, não são discutidas durante a assistência pré-natal, seja pelo desconhecimento do tema pela gestante, seja pela organização estrutural dos serviços, conforme os relatos:

\footnotetext{
A roda de gestantes me ajudou muito. Bastante [...] muitas dúvidas que eu tinha, mas também não tinha como perguntar. Eu acho que não sabia como chegar na pergunta certa. (PE8).

Porque, às vezes, a gente vai para consulta e a gente acaba se passando em alguma questão. É muita coisa. Então, eu acho que aqui é muito importante pra gente conhecer e aprender. (PE2).
}

No pré-natal, só tira dúvida assim: exame básico, escuta o coraçãozinho, mede a barriga e pronto. (PE5).

A abordagem em grupo traz, ainda, subsídios para o empoderamento das mulheres, no que tange ao seu autocuidado e ao cuidado com o seu/sua filho/a, por contribuir para estimular sua autonomia e facilitar o entendimento de sua responsabilidade como mãe:

\footnotetext{
Quando a gente faz enxoval de bebê, que a gente não tem esse preparo. Isso aqui, na verdade, eu gosto muito, porque é um empoderamento para a mulber, porque, quando a gente está bem munida, tudo fica bem mais fácil. (PE14).
} 
Então, assim foi muito bom. Aprendi coisas novas, $e$ isso eu vou levar para mim; vou levar para minha filha, quando ela tiver um filbo; para os meus netos. (PE9).

Eu aprendi a forma de coisar as mamas, de amamentar, de armazenar o leite. (PE11).

Similarmente, estudo realizado com gestantes em Sobral (CE) constatou que a condução de atividades de educação em saúde, na perspectiva problematizadora, por meio de oficinas educativas, estimulavam a exposição dos medos e dos anseios no período gestacional. Além disso, são potenciais para a emancipação das gestantes ${ }^{(6)}$.

Nessa conjuntura, notou-se que vivenciar estratégias participativas de educação em saúde propicia o fortalecimento de vínculo e confiança entre gestantes e profissionais, bem como o reconhecimento e a satisfação quanto à assistência prestada, o que mostra ser prática benéfica para ambos e importante estratégia de humanização do cuidado à saúde:

E hoje a gente tá tendo essa oportunidade. Eu não tive nada disso! Agora, a gente deve bater palmas pra elas, agradecer, muito obrigada. (PE9).

Foram super cruciais! Me atendeu super bem! Eu me senti acolbida e super informada em tudo que eu perguntei e todas as informações que me deram sem nem eu perguntar. (PE14).

Isso aqui é muito importante. Esse conbecimento todo que eu tô absorvendo aqui de quem já é mãe [...] coisa [que] eu nunca tive. (PE16).

É importante ressaltar que, na troca de experiências vivenciadas por mulheres com interesses peculiares, as orientações são facilmente compartilhadas pelo grupo, quando comparado à simples orientação profissional, pois valoriza-se o conhecimento prévio das mulheres e quebra-se o paradigma da educação tradicional e autoritária ${ }^{(8)}$.

Verificou-se também que as práticas educativas, na gestação, tornaram oportuno o reconhecimento das questões de gênero que permeiam o cuidado à saúde da criança e o puerpério, uma vez que houve estímulo à paternidade consciente como enfrentamento da desigualdade entre os gêneros, bem como valorização e fomento à perpetuação de grupos educativos:

Eu sugeri que os pais participassem pelo menos de uma [prática educativa] pra ver a importância [...] porque o marido, ele tem que participar; ele tem que saber que a responsabilidade também é dele. (PE11).
Enquanto mulheres gestantes, não deixar esse tipo de grupo não acontecer e também não morrerem, e valorizar né? Porque, lá atrás, teve mulheres gestantes e profissionais que brigaram pra isso; hoje tá acontecendo. Não se cale! (PE12).

Historicamente, todas as ações em saúde voltadas para o ciclo gravídico puerperal eram direcionadas ao público feminino. Entretanto, percebeu-se que o envolvimento masculino é fundamental para melhorar o bem-estar biopsicossocial da mãe, com reflexos no cuidado com o RN. O pré-natal, portanto, é um momento propício para problematizar as questões de gênero e encorajar o pai a participar do momento do nascimento, a clampear o cordão umbilical, a colocar $\mathrm{O} / \mathrm{a} \mathrm{RN}$ em contato pele a pele, a incentivar a amamentação e a dividir os cuidados do/a RN com a genitora ${ }^{(25)}$.

Desse modo, é oportuno frisar a relevância da propagação de novas abordagens de educação em saúde durante a gestação, que contemplem os cuidados no puerpério nos seus mais diversos aspectos, para estimular a autonomia da mulher, pondo-a como protagonista nas decisões que envolvem a sua saúde, de modo a sentir-se acolhida e valorizada ${ }^{(8)}$.

As limitações deste estudo referem-se ao fato de a investigação restringir-se às gestantes, excluindo parceiros/as e familiares na análise dos dados, e ter ocorrido em apenas uma maternidade. Acrescidos, tem-se a não identificação da idade gestacional de cada gestante, visto que estas poderiam ter outros momentos oportunos para adquirir conhecimentos sobre o seu autocuidado e o cuidado do/a RN ao longo da gestação. Faz-se necessário, portanto, a realização de estudos que envolvam gestantes, parceiros/as, familiares, bem como profissionais de saúde, para ampliar e enriquecer as discussões sobre a temática. Entre as potencialidades, destaca-se a compreensão das lacunas nos serviços de saúde e a criação de ferramentas educativas adequadas e efetivas.

\section{Considerações finais}

Este estudo descreve saberes e experiências de gestantes durante sua participação em práticas educativas dialógicas, mediante estratégias 
de problematização de comportamentos e atitudes peculiares ao período puerperal. Nesse contexto, identificou-se que, apesar de possibilitarem às mulheres desenvolverem autonomia ao retornarem ao domicílio, as atividades educativas durante o pré-natal, quando realizadas, distanciavam-se do autocuidado feminino, pois tendiam a valorizar os cuidados destinados ao $\mathrm{RN}$, sem considerar a necessidade do autocuidado da mulher. Desse modo, pressupõe-se que a escassez de orientações, somada à complexidade de fenômenos biopsicossociais que envolvem o puerpério, pode culminar com a tomada de decisões.

Verificou-se ainda que há a perpetuação de tabus e mitos concernentes ao puerpério, como a proibição da lavagem da cabeça da mulher; associação da ingestão de frutas cítricas ao refluxo no/a RN e da ingestão do milho para aumento da produção láctea; a necessidade de protrusão do mamilo, para sucção e naturalização da dor na amamentação. Embora permanecessem dúvidas em relação ao autocuidado da mulher e ao cuidado com a criança, as dinâmicas desenvolvidas nas atividades contribuíram para a reflexão e socialização de saberes e práticas.

Foi possível apreender que algumas experiências associadas ao insucesso da amamentação podiam estar relacionadas à carência de orientações, por parte dos/as profissionais de saúde, desde o período gestacional, acrescidas dos estereótipos resultantes de expectativas da sociedade. Sabe-se que o desconhecimento do manejo da amamentação contribui para o desmame precoce, além de causar traumas físicos e psicológicos nas mulheres.

Reforça-se que propiciar às gestantes a participação em grupos educativos com metodologia participativa é positivo, por oferecer inúmeros benefícios, como a troca de experiências e construção do saber em harmonia com o cotidiano do grupo. Acresce-se a isso a (re)construção de conhecimento com apoio profissional, como de enfermeiros/as, que pode impactar positivamente na experiência de amamentar, ao facilitar a adaptação, atenuar dúvidas, dificuldades e medo.
As singularidades vislumbradas pelas gestantes revelam universo rico de possibilidades para compreender as lacunas e a repercussão das ações educativas na gestação, bem como refletir sobre a atuação do/a enfermeiro/a enquanto educador/a. Os achados do estudo contribuem para a ampliação do conhecimento científico na área e para dar maior visibilidade à importância das práticas educativas em saúde, com foco nas necessidades das mulheres. Contribui, desta forma, para a construção de saberes que reflitam no seu protagonismo e autonomia durante o puerpério.

Diante da necessidade de minimizar lacunas relacionadas à desvalorização do puerpério, é necessária a realização de outras pesquisas sobre esse importante período que advém ao parto, a fim de propiciar aprimoramento profissional, sobretudo do/a enfermeiro/a. Além disso, estima-se que possam estimular a construção e análise de ferramentas educativas diferenciadas, que sirvam categoricamente como suporte para o desenvolvimento do autocuidado puerperal e do cuidado ao/à RN que resultem em mais confiança, segurança e tranquilidade por parte da mãe e de familiares.

\section{Colaborações:}

1 - concepção, projeto, análise e interpretação dos dados: Jessica Fonseca Mota, Mariza Silva Almeida, Gessica Cerqueira Magalhães e Venícia Conceição Souza;

2 - redação do artigo e revisão crítica relevante do conteúdo intelectual: Jessica Fonseca Mota, Mariza Silva Almeida, Joise Magarão Queiroz Silva e Karla Ferraz dos Anjos;

3 - aprovação final da versão a ser publicada: Jessica Fonseca Mota, Mariza Silva Almeida, Joise Magarão Queiroz Silva e Karla Ferraz dos Anjos.

\section{Referências}

1. Brasil. Ministério da Saúde. Secretaria de Atenção à Saúde. Departamento de Atenção Básica. Atenção ao Pré-natal de baixo risco [Internet]. Brasília (DF); 2012 (Cadernos de Atenção Básica, n. 32). [cited 2020 Feb 6]. Available from: http://bvsms. 
saude.gov.br/bvs/publicacoes/cadernos_atencao_ basica_32_prenatal.pdf

2. Silva EP, Lima RT, Osório MM. Impacto de estratégias educacionais no pré-natal de baixo risco: revisão sistemática de ensaios clínicos randomizados. Ciênc Saúde Coletiva. 2016;21(9):2935-48. DOI: https://doi.org/10.1590/ 1413-81232015219.01602015

3. Quental LLC, Nascimento LCCC, Leal LC, Davim RMB, Cunha ICBC. Práticas educativas com gestantes na atenção primária à saúde. Rev enferm UFPE on line. 2017;11(Supl.12):5370-81. DOI: https://doi.org/10.5205/1981-8963-v11i12 a23138p5370-5381-2017

4. Almeida ER, Moutinho CB, Leite MTS. Prática pedagógica de enfermeiros de Saúde da Família no desenvolvimento da Educação em Saúde. Interface (Botucatu). 2016;20(57):389-401. DOI: https://doi.org/10.1590/1807-57622015.0128

5. Silva ALS, Nascimento ER, Coelho EAC, Nunes IM. Atividades educativas no pré-natal sob o olhar de mulheres grávidas. Rev Cubana Enferm. 2015 [cited 2020 Feb 8];30(1):40-51. Available from: http://scielo.sld.cu/pdf/enf/v30n1/ enf05114.pdf

6. Teixeira FV, Linhares AEP, Guimarães RX, Cavalcante MMB, Lopes AIN, Teixeira MA. Oficinas educativas para um grupo de gestantes acerca do período gravídico. SANARE. 2016 [cited 2020 Feb 10];15(1):119-25. Available from: https://sanare.emnuvens.com.br/sanare/article/ viewFile/937/566

7. Bardin L. Análise de conteúdo. 6a ed. Lisboa: Edições 70; 2016.

8. Dodou HD, Oliveira TDA, Oriá MOB, Rodrigues DP, Pinheiro PNC, Luna IT. A prática educativa realizada pela enfermagem no puerpério: representações sociais de puérperas. Rev Bras Enferm. 2017;70(6):1250-8. DOI: http:// dx.doi.org/10.1590/0034-7167-2016-0136

9. Gonçalves BG, Hoga LAK. Tempo de amor e adaptação: promoção da saúde da mulher no pós-parto e do recém-nascido. São Paulo: EEUSP; 2016 [cited 2020 Feb 10]. Available from: http:// www.ee.usp.br/cartilhas/cartilha_puerperio.pdf

10. Santos FAPS, Mazzo MHSN, Brito RS. Sentimentos vivenciados por puérperas durante o pós-parto. Rev enferm UFPE on line. 2015;9(supl.2):858-63. DOI: 10.5205/reuol.6391-62431-2-ED.0902supl201512
11. Acosta MLL, Valenzuela C, Sánchez LI. Nivel de información sobre autocuidado puerperal, maternidad del Hospital Llano, Corrientes capital, año 2017. Rev Salud Pública. 2018;22(2):22-8. DOI: https://doi.org/10.31052/1853.1180.v22.n2. 20752

12. Acosta DF, Gomes VLO, Kerber NPC, Costa CFS. Influências, crenças e práticas no autocuidado das puérperas. Rev esc enferm USP [online]. 2012;46(6):1327-33. DOI: https://doi.org/10.1590/ S0080-62342012000600007

13. Scarton J, Ventura J, Rosa LS, Paula SF, Perim LF, Siqueira HCH. Cuidados de enfermagem no período pós-parto: uma abordagem ecossistêmica. Rev Enferm [Internet]. 2017 [cited 2020 Feb 12];13(13):114-23. Available from: http://revistas.fw.uri.br/index.php/revistade enfermagem/article/view/2726

14. Silva LR, Arantes LAC, Villar ASE, Silva MDB, Santos IMM, Guimarães EC. Enfermagem no puerpério: detectando o conhecimento das puérperas para o autocuidado. $\mathrm{R}$ pesq: cuid fundam online [Internet]. 2012 [cited 2020 Jan 10];4(2):2327-37. Available from: https://www. redalyc.org/pdf/5057/505750893009.pdf

15. Oliveira DR, Gomes PR, Bando AMN, Gonçalves SR. Crenças alimentares no aleitamento materno. Um estudo entre gestantes e nutrizes atendidas em uma maternidade pública no município de São Paulo. Arq Bras Ciênc Saúde [Internet]. 2011 [cited 2020 Feb 8];36(2):67-71. Available from: http://files.bvs. br/upload/S/1983-2451/2011/v36n2/a2196.pdf

16. World Health Organization. Maternal mortality. Ten steps to successful breastfeeding [Internet]. Geneva (CH); 2019 [cited 2020 Feb 20]. Available from: https://www.who.int/news-room/factsheets/detail/maternal-mortality

17. Carrera S. Intervención educativa para mejorar los conocimientos del autocuidado en puérperas. CASUS [Internet]. 2018 [cited 2020 Feb 20];3(3):161-6. Available from: https://dialnet. unirioja.es/servlet/articulo?codigo $=6756084$

18. Ferreira AP, Dantas JC, Souza FMLC, Rodrigues IDCV, Davim RMB, Silva RAR. O enfermeiro educador no puerpério imediato em alojamento conjunto na perspectiva de Peplau. Rev Eletr Enf. 2018;20:v20a08. DOI: http:// doi.org/10.5216/ree.v20.45470 
19. Andrade LCO, Santos MS, Aires JS, Joventino ES, Dodt RCM, Ximenes LB. Conhecimento de puérperas internadas em um alojamento conjunto acerca da higiene do neonato. Cogitare Enferm [Internet]. 2012 Jan/Mar [cited 2020 Feb 8];17(1):99-105. Available from: https://revistas.ufpr.br/cogitare/article/ viewFile/26381/17574

20. Vasconcelos ML, Pessoa VLMP, Chaves EMC, Pitombeira MGV, Moreira TMM, Cruz MR, et al. Cuidado à criança menor de seis meses no domicílio: experiência da mãe primípara. Esc Anna Nery. 2019;23(3):e20180175. DOI: 10.1590/2177-9465-EAN-2018-0175

21. Cesar JA, Acevedo JD, Kaczan CR, Venzo JCP, Costa LR, Silva LCM, et al. Intenção das mães em colocar o bebê para dormir em decúbito dorsal: um estudo de base populacional. Ciênc saúde colet. 2018;23(2):501-8. DOI: https://doi. org/10.1590/1413-81232018232.20732015

22. Schultz SM, Moreira KFA, Pereira PPS, Ferreira LN, Rodrigues MAS, Fernandes DER. Influência da educação em saúde na autoeficácia em amamentar: estudo quase experimental. Rev baiana enferm. 2020;34:e35995. DOI 10.18471/rbe. v34.35995
23. Prado CVC, Fabbro MRC, Ferreira GI. Desmame precoce na perspectiva de puérperas: uma abordagem dialógica. Texto Contexto Enferm. 2016;25(2):e1580015. DOI: http://dx.doi.org/10. 1590/0104-07072016001580015

24. Brasil. Ministério da Saúde. Secretaria de Atenção à Saúde. Departamento de Atenção Básica. Saúde da criança: aleitamento materno e alimentação complementar [Internet]. Brasília (DF); 2015 (Cadernos de Atenção Básica, no 23). [cited 2020 Feb 6]. Available from: https://bvsms.saude.gov. br/bvs/publicacoes/saude_crianca_aleitamento_ materno_cab23.pdf

25. Brasil. Ministério da Saúde. Secretaria de Atenção à Saúde. Departamento de Ações Programáticas Estratégicas. Guia do Pré-Natal do Parceiro para Profissionais de Saúde [Internet]. Brasília (DF); 2016 [cited 2020 Feb 6]. Available from: http:// www.saude.gov.br/images/pdf/2016/agosto/11/ guia_PreNatal.pdf

Recebido: 2 de outubro de 2020

Aprovado: 12 de janeiro de 2021

Publicado: 9 de fevereiro de 2021

A Revista Baiana de Enfermagem utiliza a Licença Creative Commons - Atribuição-NãoComercial 4.0 Internacional. https://creativecommons.org/licenses/by-nc/4.0/ Este artigo é de acesso aberto distribuído sob os termos da Licença Creative Commons (CC BY-NC). Esta licença permite que outros remixem, adaptem e criem a partir do seu trabalho para fins não comerciais. Embora os novos trabalhos tenham de lhe atribuir o devido crédito e não possam ser usados para fins comerciais, os usuários não têm de licenciar esses trabalhos derivados sob os mesmos termos.: 